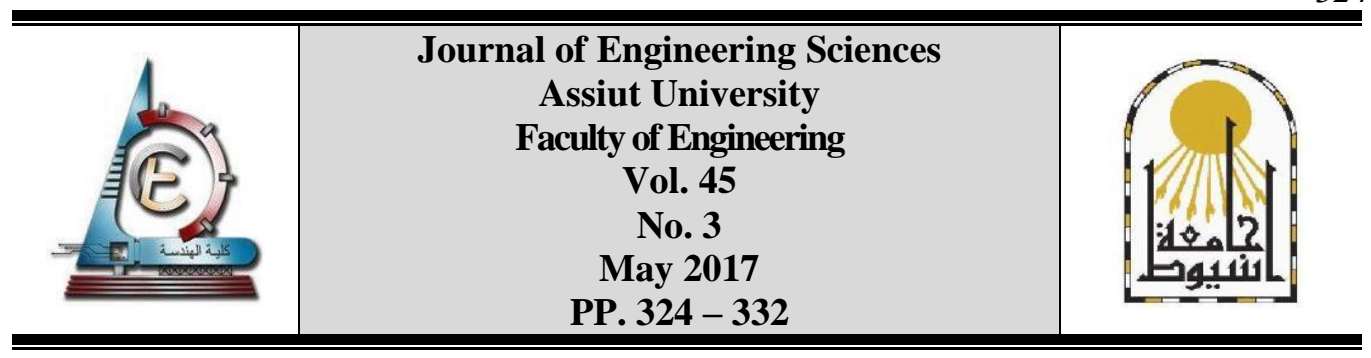

\title{
ENHANCING THE SURFACE ROUGHNESSOF FUSED DEPOSITION MODELING PRODUCTS
}

\author{
M. Adel *, Osama, Abdelrasoul, Abu Bakr, Aboel Makaram \\ Mechanical Eng. Dept., Faculty of Engineering, Assiut University, Assiut, Egypt
}

Received 9 March 2017; Accepted 23 April 2017

\begin{abstract}
Fused deposition modeling (FDM) is the most versatile additive manufacturing technology owing to the low-cost materials that handle. However, FDM produce very rough parts which limit its use in molds and other industrial applications owing to stair-case effect. To obtain smoother surfaces, a post-processing phase may be introduced. In this research, a non-contact finishing process to FDM parts using hot air was developed. The hot air is directed locally at the stair-case in the surface till melting it which results after cooling to a smoother surface. An experimental setup was constructed to study the effects of different process parameters including air temperature, air flow rate and the moving velocity of air nozzle over parts surface. An improvement in the Roughness Average of a surfaces measured microscopic peaks and valleys (Ra) down to values of sub-micron was recorded from specimens with average surface roughness from7 to $8 \mu \mathrm{m}$.
\end{abstract}

Keywords: fused deposition modeling -surface roughness- non-contact machining.

\section{Introduction}

Nowadays, Additive manufacturing (AM) technologies become a way of batch production of complex parts. The technology reduces the lengthy steps of traditional manufacturing and presents a progress toward rapid manufacturing. Researches on additive manufacturing techniques focus on aspects like part strength, surface roughness, and materials used to obtain similar quality like traditional techniques. One of the most common techniques in AM is FDM owing to its simplicity and lowmanufacturingcost. The technology deals with wide range of polymer-based material sand may also non-polymer materials which under research phase. FDM machinemanufactures parts by extruding a semi-molten filament material through a robotically controlled nozzle in machine head; the nozzle heats and extrudes the material while the machinehead is movingto deposit the layers of the part [1]. Figure 1 presents the manufacturing technique and its main components. This layer-based

Manufacturing yields to a stair-like surface in all AM techniques. Hence, AM techniques and specially FDM are characterized with higher surface roughness comparing with traditional manufacturing techniques [2]. 


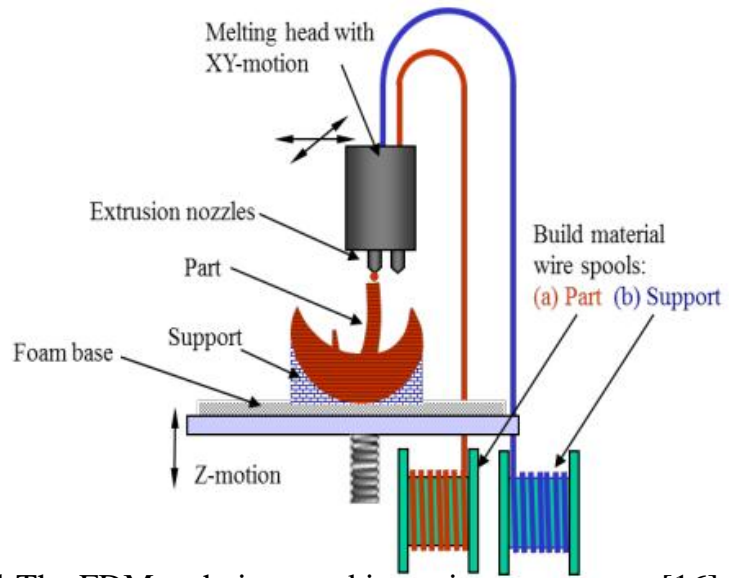

Fig. 1.The FDM technique and its main components [16]

Several studies were presented to smooth the FDM part surfaces employing different machining techniques. A simple hot cutting machining process is used [3].The process composed of a heated knife edge directed to the surface with a rake angle like a lathe cutting tool; The process improves the surface roughness but it may affect much on dimensional accuracy and may be applicable to high roughness values. Galantucci et al. [4] use a chemical method for surface smoothening where the part surfaces made of Acrylonitrile Butadiene Styrene (ABS) are treated with acetone; The best process parameters obtained are immersing time of 300 second and solvent concentration of 10\%acetone in water. Stratasys company [5] presents a new chemical technique named vapor smoothening method; the technique deposits the vapor of a chemical etching material on the surface of the part; the technique improves significantly the Ra values of ABS parts but may need time, preparations, and the use of proper etching material (if available). Leong et al. [6] present abrasive jet deburring process applied on stereo-lithography parts. The process exerts a stream of high-velocity abrasive particles at part-burrs until it becomes eroded. The process improves the surface Ra value if proper optimization was held to process parameters otherwise, increase in roughness will result. Recently, an abrasive technique [7] uses barrel finishing to FDM parts but the technique needs hours to perform in a rotating room contains barrels. The previous literature shows that most post processing techniques such as abrasive techniques. Although there are some other techniques are surface addition techniques like painting or coating methods but, it mostly requires an abrasive technique before. Abrasive techniques introduce tools, cutting forces, and abrasion material. In the other side, The presented finishing process is neither abrasive nor additive and can results to highly smooth surfaces.

\section{Process description}

The target of the developed finishing process is to locally re-meltsthe surface of FDM parts using a jet of hot air. The re-melting will fuse the stair-case (the stair tips) in the surface of FDM parts and will leave the surface free of stairs. In this condition,the heated jet temperaturewas sustainedat highertemperature than the melting temperature ofpart 
material; and forcontinuous processing operation, the nozzle introducing hot air which moves over partsurface with appropriate translational velocity; this translational velocity should be lower enough to heat the surface till melting.

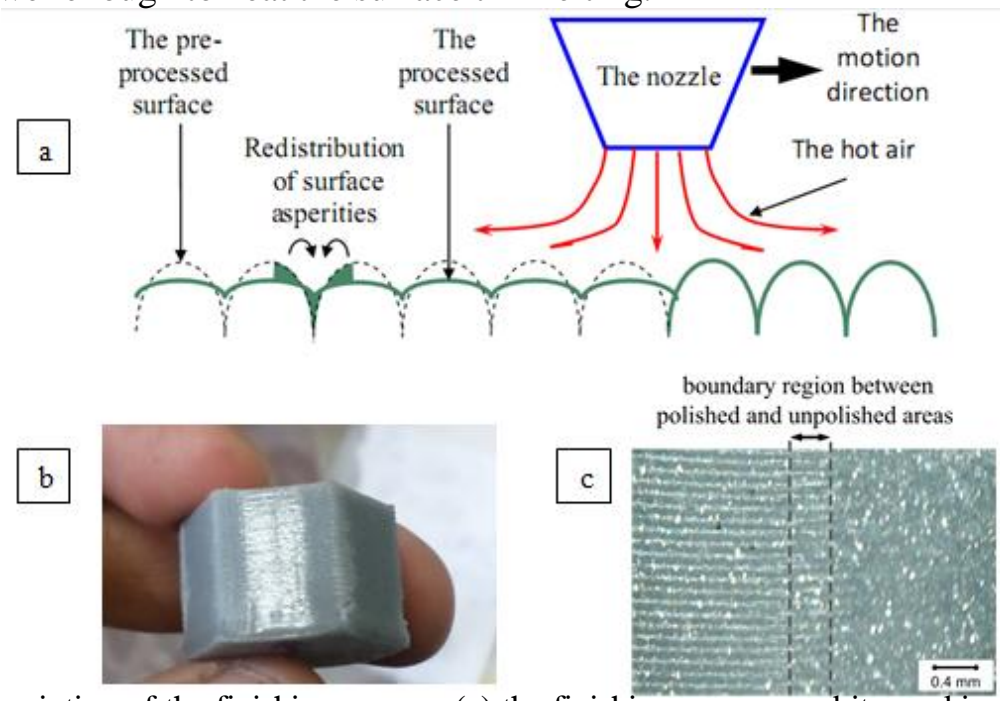

Fig. 2. Description of the finishing process (a) the finishing process and its working principle (b) a picture of experimentally finished surface (c) microscopic picture at boundary region of surface at (b)

The hypothesis of roughness improvement is that: when hot air melts this staircase, it will be free to move under surface tension force. Surface tension tends to heal and flatten this staircase and cause -after cooling- a reductionin surface roughness. This finishing concept is the same as that in laser polishing technique where the laser light is the heating source instead of hot air. The laser polishing technique is often used with hard metals like diamond or titanium alloys where abrasive tools are no longer appropriate [8]. Figure $2 \mathrm{a}$ presents a schematic to the process while figure $2 b$, shows a magnification of an experimentally processed surface with hot air.

One advantage of using hot air finishing instead of laser is that laser system introduces high initial cost compared with the price of FDM parts. Also-for possible manual application-finishing by hot air is safer than laser.

\section{Materials and methods}

Figure $3 \mathrm{a}$ shows a schematic diagram of the main test rig components. The test rig introduces filtered air with a controlled flow rate and temperature on a moving FDM specimen -and the air nozzle is fixed- with a controlled translational velocity. To achieve that, fresh air exits from the compressor tank and passes through an air filter and later through a pressure regulator. After that, the filtered air passes through a flow controller and then to a heater and finally exits from the air nozzle to the surface to be processed. Another additional components were introduced at the experimental setup shown in figure $3 \mathrm{~b}$; these components involve the use of Z-axis in the used 3-D printer (shown in the figure) to provide the part with a translational velocity relative to air nozzle. Also, a frictionless x-y suspension 
placed in the top of the printer to hang the heater and other components. Finally, a vice is used for fixing and aligning the test specimen relative to the jet of heated air.
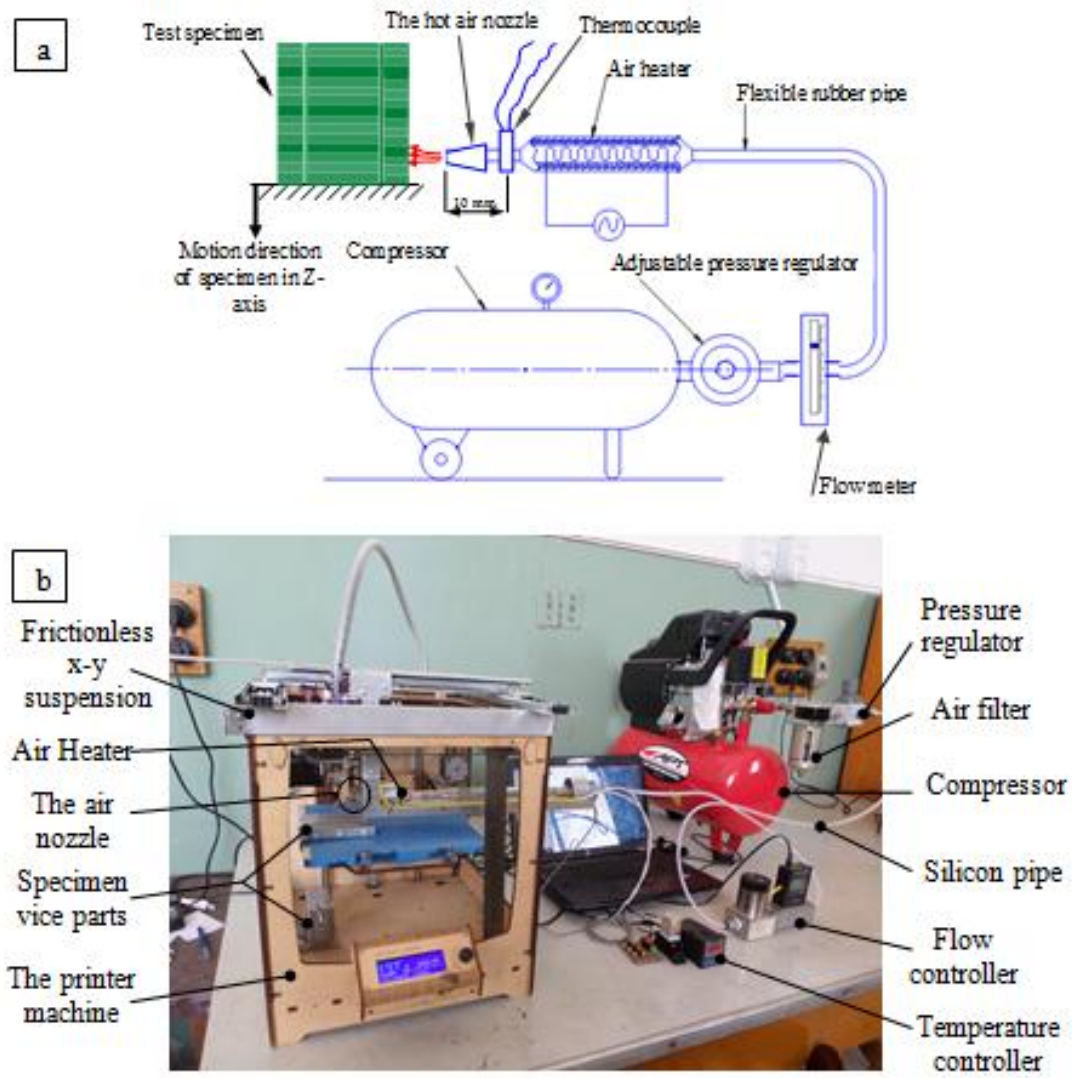

Fig. 3.The test rig of the proposed finishing technique (a) schematic diagram (b) the experimental setup

The used flow meter is an industrial type of Alicate mass/volume flow meter/controller while the body of the heater is made from a high heat-resistance transparent glass for easy troubleshooting and it uses a nickel-chrome coil which is connected to an industrial on/off controller using a $\mathbf{J}$ type thermocouple. Thermocouple was installed near to the air nozzle opening (about $1 \mathrm{~cm}$ )to indicate the air exit temperature. the parts; exit hose of the heater, thermocouple connection, and air nozzle are thermally insulated with ceramic fiber so that the obtained air exit temperatures are with good accuracy.

The remaining of this section will discussion the test conditions that must prevail to regenerate the presented results. The motion direction of machining process done by air nozzle is the same as the deposition direction. The hot air exiting from the nozzle is at a right angle to the processed face. Its diameter (d) is $2.5 \mathrm{~mm}$ and the opening is at an apparent distance (L) of $5 \mathrm{~mm}$ from the processed surface.

Figure 4a shows the test specimen. The tested FDM specimens were made of PolyLactic Acid (PLA) uses 3-D printing machine (Ultimaker original). The melt temperature of PLA within manufacturing is $200 \mp 8^{\circ} \mathrm{C}$ [9]-[11]. The specimen has a hexagonal base 
with edge of $13 \mathrm{~mm}$ and a height of $21 \mathrm{~mm}$. This shape ensures six side faces that can be processed. The specimen shape was simple exclude further complications related to the shape or surface angle. Also, the processed surfaces/faces of specimens have a sufficient wall thickness of larger than $2.5 \mathrm{~mm}$;
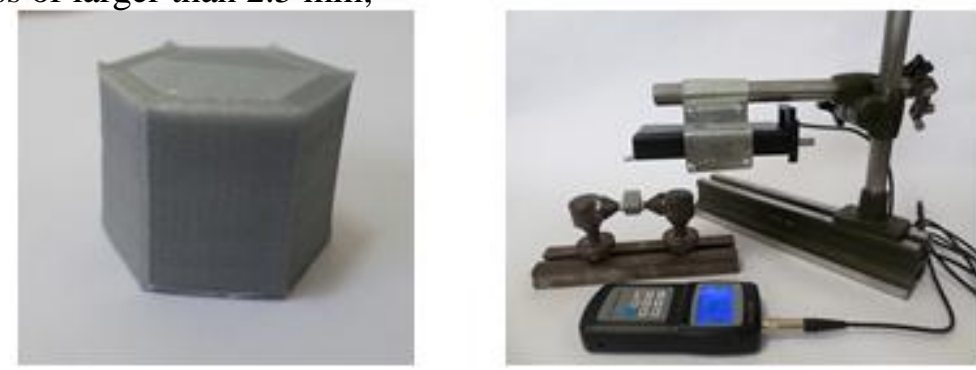

Fig. 4. (a) The test specimen (b) the roughness measuring set up

The pre-processed roughness in Ra (of specimen faces) is varied from 7 to $8 \mu \mathrm{m}$ while faces with Ra values other than that are excluded. This roughness value is attained by using a layer thickness around $0.1 \mathrm{~mm}$. The obtained surface roughness values are in Ra were measured by "6210s digital portable roughness tester". Figure 4b shows the roughness measuring set up. It is a mechanical stylus type profile meter with accuracy down to less than 10 percent of its full scale. The measurements are carried out around faces mid-plane which is the place of processing with hot air.

\section{Results and discussion}

Now, the process variables were reduced to three input parameters: air temperature, air flow rate, and air nozzle translational velocity. These parameters will be tested with the resulting roughness improvements. Other possible process-parameters are mentioned in section 4and they were held constants over different tests.

\subsection{The resulting surface roughness at constant air temperature}

Figure 5 describes the variation of the average achieved reduction ratio at constant temperature of $235^{\circ} \mathrm{C}$ while nozzle velocity and air flow rate varies. Every point in the figure represents a finished surface under certain combination between nozzle velocity, air flow rate while air temperature is $235^{\circ} \mathrm{C}$.At vertical axis, there is the average achieved Ra reduction $\%$ calculated by:

$$
\mathrm{Ra} \text { reduction } \%=\left[100 *\left(\mathrm{Ra}_{\text {preprocessing }}-\mathrm{Ra}_{\text {postprocessing }}\right) / \mathrm{R} \mathrm{a}_{\text {preprocessing }}\right]
$$

The horizontal axis represents the nozzle velocity over test surface. The figure contains five curves that each one was held under constant flow rate. The shown Ra values are measured with $\mathrm{RC}$ filtering( $\mathrm{RC}$ filtering is a traditional 2-stage filter with phase difference).The filtering gives more stable/precise results indicating roughness only of the measured surface and excluding other features like inclination and waviness. Filtering with RC was used with all the data presented in figure 5 except ones with negative reductions as will be explained. 


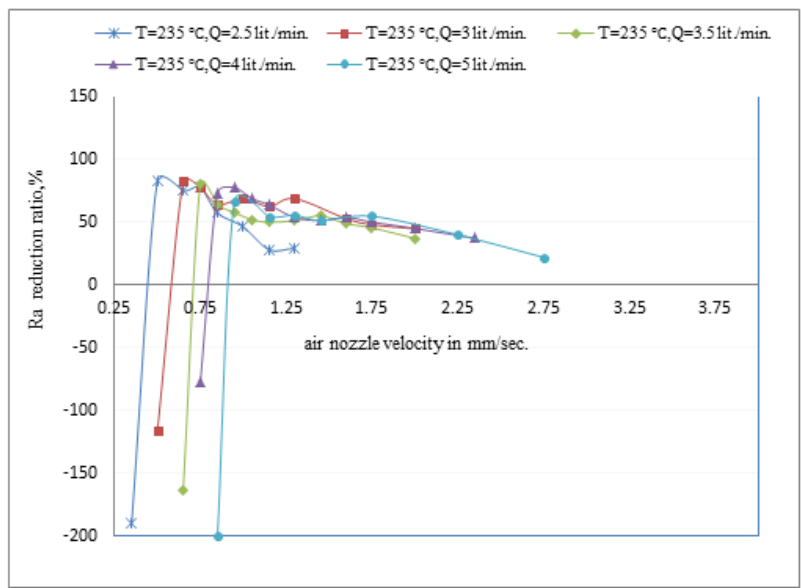

Fig. 5. Variations of nozzle velocity and the resulting $\mathrm{Ra}$ at constant air temperature

The main result noted in figure 5 is that the reduction in Ra values continues to increase with decreasing the nozzle velocity till a maximum allowable value and then further decrease in nozzle velocity results to local waviness and/or possibly scattered holes in the surface similar to pitting. Figure 6 presents pictures of the two described surfaces (the maximum allowable reduction and the failed ones). This condition determines the maximum possible nozzle velocity at certain combination between air temperature and air flow rate; this condition is represented in figure 5 by negative reduction percent. Also, it is noted that further increase in air temperature or air flow rate under this conditions will also cause this failure mode to the surface especially, the increase in air flow rates. When this failed surface/face is measured by RC filtering, it probably gives average roughness values similar to the maximum reduction point showing that filtering excludes the introduced waviness and makes the two cases are similar. To distinguish between these two conditions, another reading with roughness meter using DP (Digital Primary profile - no filtering) was taken beside reading with RC filtering todetect the introduced waviness. Fortunately, DP detects the beginning of waviness represented in figure 5 by negative reduction values -measured by DP- while it continues to detect a positive reduction in Ra reading similar to $\mathrm{RC}$ filtering in the remaining point of the figure - which measured by RC.

It is observed from figure 5 that the increase in air flow rate shifts the entire curve to the right; in other words, it increases the allowable operating nozzle velocity which permits faster finishing process. Another important finding is that the maximum achieved reduction reduces with increasing flow rate as the maximum achieved $\mathrm{Ra}$ reduction corresponds to minimum flow rate and vice versa. This observation is obtained by noting the maximum reduction points in every curve in figure 5.

\subsection{The resulting surface roughness at constant flow rate}

Figure 7describes the variation of the average achieved reduction ratio at constant air flow rate of 3.5 liter/min. while nozzle velocity and air temperature varies. Similar to figure 5 , every point infigure7 represents a finished surface under certain test conditions. The vertical axis represents the average achieved Ra reduction\% calculated by equation (1). Also, the shown Ra reduction ratios are 
measured using Ra readings by $\mathrm{RC}$ filtering except the ones with negative reductions which are measured using DP. Figure 7 verifies the observation obtained from figure 5 which state that: there is an allowable range of nozzle velocity over the surface, while lower velocities will deteriorate the surface in form of high waviness and/or local scattered holes similar to pitting. In other side, much high nozzle velocity may not smooth the surface. This repeated observation is similar to a concept in laser polishing process. It is known that there are two operating levels of energy in laser polishing. The first is surface shallow melting (SSM) [12] which represents an appropriate range of energyrate of laser beam that introduces adjacent Ra improvement. The second is surface over melting (SOM) which is characterizedby higher energy rate of laser beam with increased roughness values of the processed surface [13]. Ramos et al. [14] presents further investigation to SOM regime.

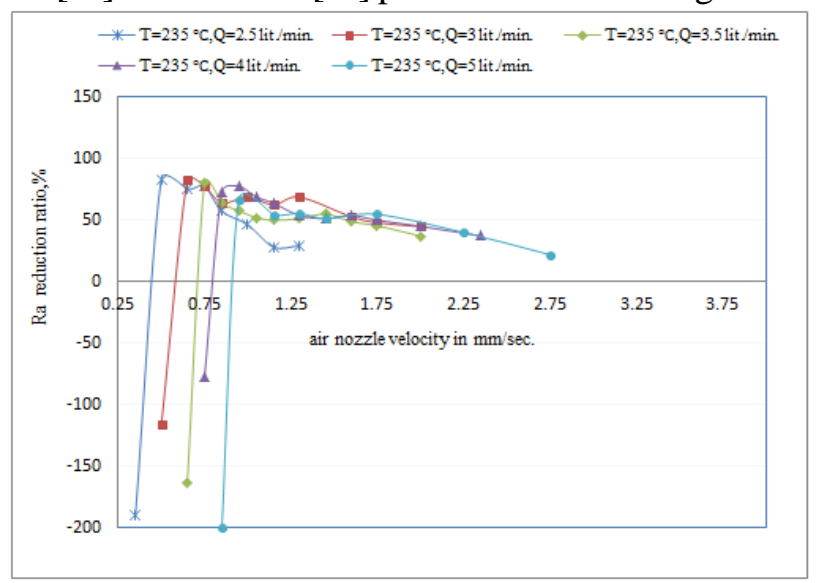

Fig. 7. Variations of nozzle velocity and the resulting Ra at constant air flow rate

The figure illustrate that the increase in air temperature shifts the entire curve to the right; in other words, permits faster finishing process. This behavior also repeated for air flow rate(in figure 5). To demonstrate this behavior, see Lamikiz et al. [15]. This study verifies that SSM regime is attained by sustaining an optimum energy level delivered to the surface by polishing process. Higher energy levels lead to SOM regime. Hence, the process parameters must accommodate in between to sustain this level. On other words, the increase in air temperature is compensated by the increase in nozzle velocity (or decrease in exposure time).

Figure 7 demonstrates the maximum achieved reduction increases with air temperature. Also high temperature finishing (figure 7) can last effective on the finished surface than high flow rate one. In figure 7 , a reduction more than $25 \%$ may attained for velocities higher than $2.75 \mathrm{~mm} / \mathrm{sec}$. while it is lower than $25 \%$ at this velocity in high flow rate. This makes sense as the temperature difference is the main driving force for melting and consequently, smoothing. If much low flow rate and high temperature is used, the surface will be smooth but the reversed condition will not result to any smooth surface.

\section{Conclusion}

In this study, a post-processing technique was presented to enchance the surface roughness of FDM parts. The technique uses hot air to melt the microscopic corners of the staircase surface. The results show that the technique has a significant effect on the resulting Ra where a reduction in Ra values of about $88 \%$ was recorded. There is allowable nozzle velocity for every 
used combination between air temperature and air flow rate. A lower velocity than allowable causes overheating which causes surface waviness with the possibility of surface pitting; while a higher velocity causes lower Ra reduction values or possibly no improvements.

Nine combination of air temperature and air flow rate is presented with its corresponding nozzle velocities; this provides the required data for use with air temperatures within $215-265^{\circ} \mathrm{C}$ and with air flow within $2.5-5$ lit./min.

\section{Acknowledgement}

This study was funded by "Science and Technology Development Fund; (STDF)" office, The Egyptian Ministry of State for Scientific Research (Grant type: RSTDG, project IP: 12612). The authors thank the "Industrial Technology Transfer Unity; (ITTU)" office in Assuit University for their technical support.

\section{REFERENCES}

[1] Y. Yan et al., "Rapid Prototyping and Manufacturing Technology: Principle, Representative Technics, Applications, and Development Trends," Tsinghua Sci. Technol., vol. 14, no. June, pp. 1-12, Jun. 2009.

[2] D. Pal and B. Ravi, "Rapid tooling route selection and evaluation for sand and investment casting," Virtual Phys. Prototyp., vol. 2, no. 4, pp. 197-207, Dec. 2007.

[3] P. Pandey, N. Reddy, and S. Dhande, "Improvement of surface finish by staircase machining in fused deposition modeling," J. Mater. Process. Technol., vol. 132, 2003.

[4] L. M. Galantucci, F. Lavecchia, and G. Percoco, "Experimental study aiming to enhance the surface finish of fused deposition modeled parts," CIRP Ann. - Manuf. Technol., vol. 58, no. 1, pp. 189-192, Jan. 2009.

[5] R. L. Zinniel, "Vapor smoothing surface finishing system," Google patents, US8075300 B2, 2011.

[6] K. F. Leong, C. K. Chua, G. S. Chua, and C. H. Tan, "Abrasive jet deburring of jewellery models built by stereolithography apparatus ( SLA )," J. Mater. Process. Technol., vol. 83, no. C, pp. 36-47, 1998.

[7] A. Boschetto and L. Bottini, "Surface improvement of fused deposition modeling parts by barrel finishing," Rapid Prototyp. J., vol. 21, no. 6, pp. 686-696, Oct. 2015.

[8] E. Bordatchev, "Performance of laser polishing in finishing of metallic surfaces," Int. J. Adv. Manuf. Technol., vol. 73, no. 1, pp. 35-52, 2014.

[9] D. Garlotta, "A literature review of poly (lactic acid)," J. Polym. Environ., vol. 9, no. 2, pp. 2005-2008, 2001.

[10] M. Pyda, R. . Bopp, and B. Wunderlich, "Heat capacity of poly(lactic acid)," J. Chem. Thermodyn., vol. 36, no. 9, pp. 731-742, Sep. 2004.

[11] "Moldflow Material Testing Report - NatureWorks LLC." [Online]. Available: http://www.natureworksllc.com/ /media/Technical_Resources/Properties_Documents/Prop ertiesDocument_7000DMoldFlowReport_pdf.pdf. [Accessed: 09-Jan-2017].

[12] a. Lamikiz, J. a. Sánchez, L. N. López de Lacalle, and J. L. Arana, "Laser polishing of parts built up by selective laser sintering," Int. J. Mach. Tools Manuf., vol. 47, no. 12-13, pp. 2040-2050, Oct. 2007.

[13] J. Ramos, D. Bourell, and J. Beaman, "Surface over-melt during laser polishing of indirectSLS metal parts," in MRS Proceedings, 2002, vol. 758.

[14] J. A. Ramos, D. L. Bourell, and J. J. Beaman, "Surface over-melt during laser polishing of indirect-SLS metal parts," MRS Proc., vol. 758, 2002.

[15] A. Ã. Lamikiz, J. A. Sanchez, L. . L. Lacalle, and J. A. Arana, J LSa, "Laser polishing of parts built up by selective laser sintering," Int. J. Mach. Tools Manuf., vol. 47, no. C, pp. 2040-2050, 2007.

[16] A. S. Rao, M. Dharap, J. Venkatesh, and D. Ojha, Investigation Of Post Processing Technbiques To Reduce The Surface Roughness Of Fused Deposittion Molding Parts," Int. J. Mech. Eng. Technol., vol. 3, no. 3, pp. 531-544, 2012. 
تحسين خشونة سطح المنتجات المصنعة بتكنولوجيا الإذابة والترسيب

الملخص:

تعد تكنولوجيا الإذابة و الترسيب الأشهر بين طرق التصنيع بالإضافة بسبب تعاملها مع مو اد مختلفة قليلة

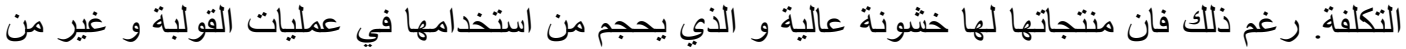

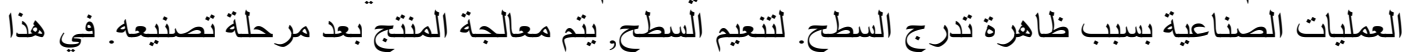

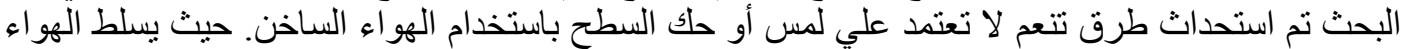

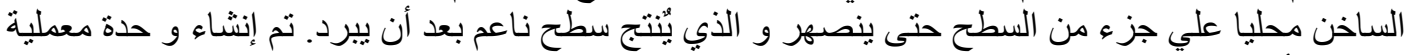

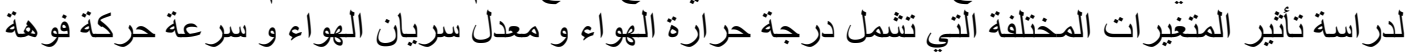
الهو اء فوق سطح المنتج. تم تسجيل انخفاض في قيم الخشونة (بمقياس Ra) اقل من 1 ميكرومثر من عينات

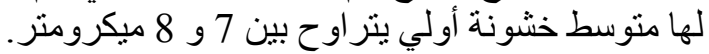

